Supporting Information

\title{
Influence of Perovskite Interface Morphology on the Photon Management in Perovskite/Silicon Tandem Solar Cells
}

Wayesh Qarony ${ }^{1, \dagger}$, Mohammad I. Hossain ${ }^{1, \dagger}$, Vladislav Jovanov ${ }^{2}$, Alberto Salleo $^{3}$, Dietmar Knipp ${ }^{3, *}$, Yuen Hong Tsang ${ }^{1,{ }^{*}}$

1.) Department of Applied Physics, The Hong Kong Polytechnic University, Hung Hom, Kowloon, Hong Kong

2.) Research Center for Functional Materials and Nanomolecular Science, Jacobs University Bremen, 28759 Bremen, Germany

3.) Geballe Laboratory for Advanced Materials, Department of Materials Science and Engineering, Stanford University, Stanford, CA 94305, USA

$\dagger:$ W. Q. and M.I.H. are equally contributed to this work

*.) Corresponding authors: E-mail: yuen.tsang@polyu.edu.hk (Y. H. Tsang), dknipp@stanford.edu (D.K) 

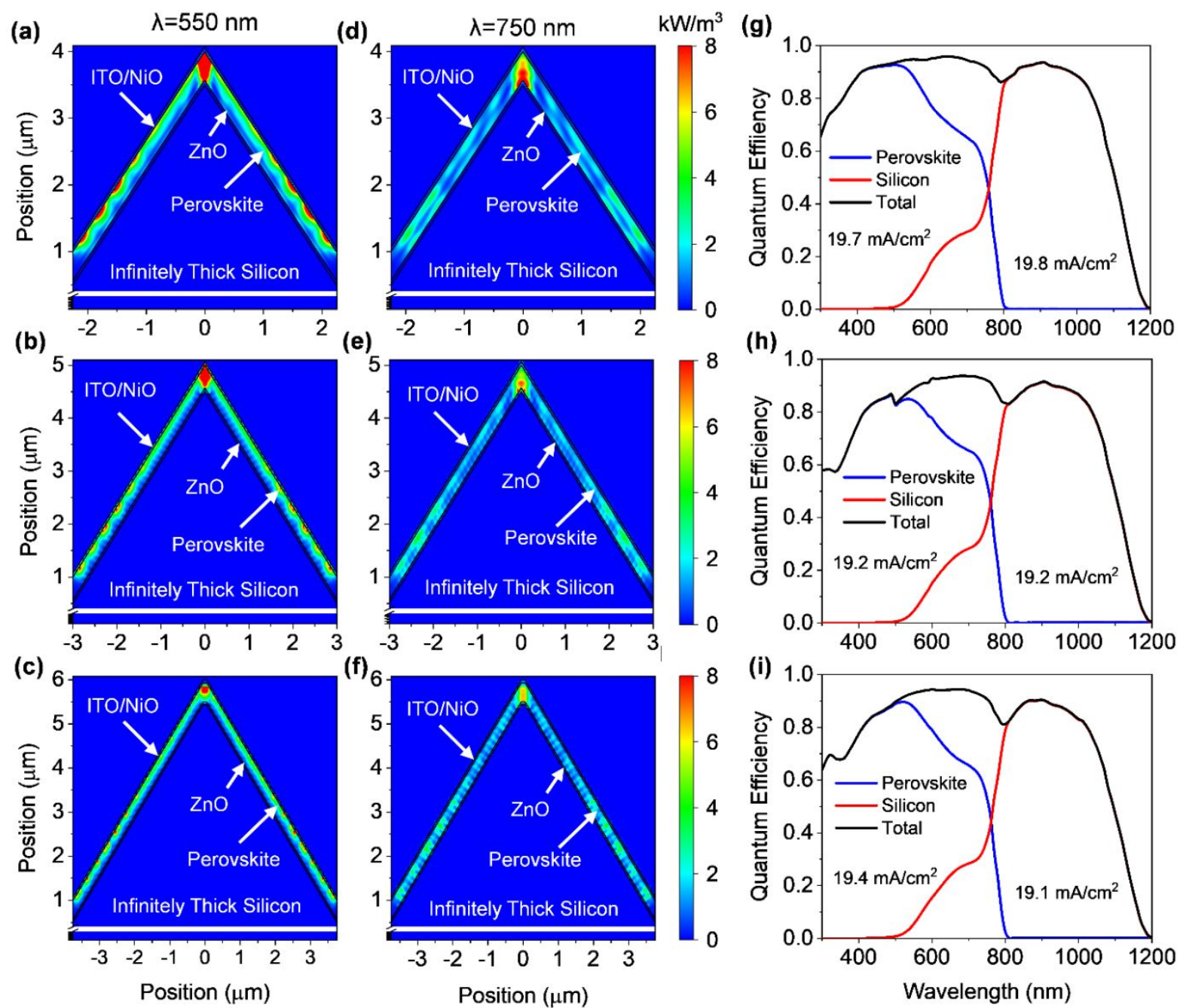

Figure S1: Power density distribution of perovskite top solar cells of perovskite/silicon tandem solar cell for film growth in the direction of the substrate normal for an incident wavelength of (a-c) $550 \mathrm{~nm}$ and (d-f) $750 \mathrm{~nm}$. Different pyramid texture periods of $(\mathrm{a}, \mathrm{d})$ $4500 \mathrm{~nm},(\mathrm{~b}, \mathrm{e}) 6000 \mathrm{~nm}$, and (c,f) $7500 \mathrm{~nm}$ are used for the investigation, where period to height ratio is kept constant. 